\title{
Cerebral oxygenation and white matter injury: Pieces in a puzzle unsolved
}

\author{
Scott M. Bradley, MD
}

From the Section of Pediatric Cardiac Surgery, Medical University of South Carolina, Charleston, SC.

Disclosures: Author has nothing to disclose with regard to commercial support.

Received for publication May 20, 2018; revisions received May 20, 2018; accepted for publication May 22, 2018; available ahead of print July 4, 2018.

Address for reprints: Scott M. Bradley, MD, Pediatric Cardiac Surgery, Medical University of South Carolina, CSB 424, 96 Jonathan Lucas St, Charleston, SC 29425 (E-mail: bradlesm@musc.edu).

J Thorac Cardiovasc Surg 2018;156:1654-6

0022-5223/\$36.00

Copyright (C) 2018 by The American Association for Thoracic Surgery

https://doi.org/10.1016/j.jtcvs.2018.05.089

White matter injury detected by brain magnetic resonance imaging (MRI) is now recognized to be a common finding both before and after cardiac surgery in neonates. In 2 previous studies, investigators from the Children's Hospital of Philadelphia (CHOP) have reported that older age at surgery is associated with white matter injury, characterized by periventricular leukomalacia (PVL). ${ }^{1,2}$ Among 26 neonates with transposition of the great arteries (TGA), a longer time to surgery was independently associated with PVL on preoperative brain MRI. ${ }^{1}$ The mean time to surgery was 5.6 days among patients with PVL, versus 3.9 days among those without PVL. In a subsequent study, 37 neonates with hypoplastic left heart syndrome (HLHS) underwent brain MRI both before and approximately 1 week after stage 1 palliation. ${ }^{2}$ A longer time from birth to surgery was independently associated with the development of new or worsened postoperative PVL. The mean time to surgery was 5.3 days among those with a large volume of acquired postoperative PVL, versus 3.1 days among those with a small volume or no new PVL. ${ }^{2}$ These findings are provocative, especially given the age at surgery for patients with TGA and HLHS in current practice. In the most recent data from the Society of Thoracic Surgeons Congenital Heart Surgery Database, the median age at surgery was 6 days for both an arterial switch and a Norwood procedure. ${ }^{3}$ The mechanisms underlying an association between older age at surgery and white matter injury are not known. This knowledge gap serves as an impetus for further study of preoperative cerebral blood flow and oxygenation.

In this issue of the Journal, Lynch and colleagues ${ }^{4}$ from CHOP examine cerebral hemodynamics between the time of birth and surgery in neonates with either TGA or HLHS. Lynch and colleagues ${ }^{4}$ used a custom-made optical instrument that combines 2 distinct near-infrared light techniques, diffuse optical spectroscopy (DOS) and diffuse correlation spectroscopy (DCS). DOS is akin to the commercially available near-infrared spectrographic (NIRS) devices now in widespread use. The commercial

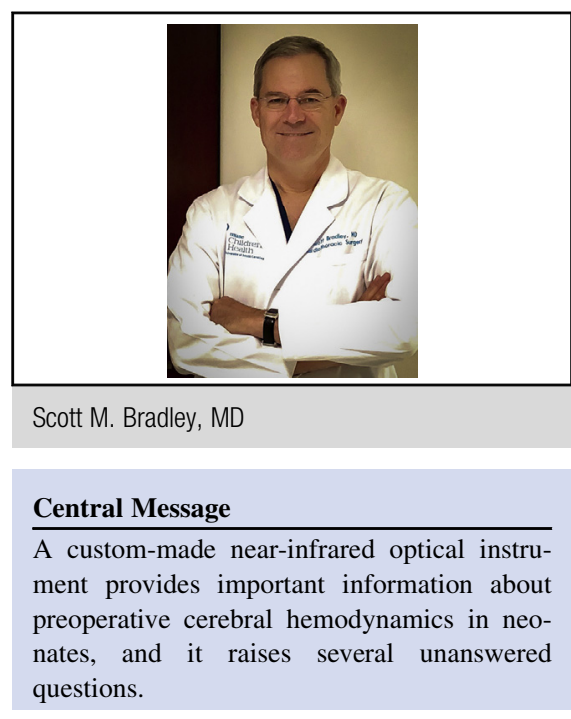

See Article page 1657.

devices measure the attenuation of continuous-wave nearinfrared light. This measurement is sensitive to ambient, room light and is affected by both tissue absorption and scattering. ${ }^{5}$ The commercial devices provide reliable trends but not absolute values of cerebral oxygenation. In contrast, DOS uses frequency domain or modulated near-infrared, rather than continuous-wave NIRS, and provides measurement of absolute levels of cerebral oxyhemoglobin and deoxyhemoglobin. From these, a value for cerebral oxygen saturation is derived $\left(\mathrm{ScO}_{2}\right)$. The DOS algorithm is less influenced by light scatter, and it gives a reliable absolute value for $\mathrm{ScO}_{2}{ }^{5}$ DOS has been validated in both animals and humans. ${ }^{6-8}$ In a study of children undergoing cardiac catheterization, $\mathrm{ScO}_{2}$ was found to be related to both arterial and jugular venous bulb saturation, with an arterial contribution of $16 \%$ and a venous contribution of $84 \%$.

DCS quantifies temporal fluctuations in reflected nearinfrared light, which are largely caused by the motion of red blood cells. ${ }^{5}$ This allows derivation of a tissue blood flow index (BFI). BFI is in different units from blood flow $\left(\mathrm{cm}^{2} / \mathrm{s}\right)$ and is not a measure of absolute flow. Relative changes in BFI, however have been found to reflect relative changes in blood flow. ${ }^{5}$ DCS has also been validated in both animals and humans. BFI has been found to correlate with cerebral blood flow measured by MRI in the superior sagittal sinus of neonates with TGA and HLHS, ${ }^{8}$ as well 
as the jugular veins and superior vena cava of children with functional single-ventricle heart defects. ${ }^{9}$ BFI has also been found to correlate with cerebral blood flow measured by xenon-enhanced computed tomography in adults with head injury, ${ }^{10}$ transcranial Doppler ultrasonography in premature infants, ${ }^{11}$ and fluorescent microspheres in piglets. ${ }^{12}$

The current study by Lynch and colleagues ${ }^{4}$ includes 48 neonates, 24 with TGA and 24 with HLHS. Optical measurements were made once daily for a mean of 4 days and stopped once the patient went to surgery. $\mathrm{ScO}_{2}$ was determined by DOS, and BFI was determined by DCS. Arterial oxygen saturation and hemoglobin levels were also measured. From these values, cerebral oxygen consumption and oxygen extraction fraction were derived. The primary finding of the study is that $\mathrm{ScO}_{2}$ decreased over time, with a mean decrease of $2.2 \%$ per day. BFI and cerebral oxygen consumption did not change. The decrease in $\mathrm{ScO}_{2}$ resulted in a corresponding increase in the calculated oxygen extraction fraction. Several limitations of the study deserve mention. Measurements were made only once per day, so possible intervening fluctuations were not taken into account. Several factors that may affect cerebral blood flow were not detailed, including ventilatory support, sedative medications, blood pressure, and carbon dioxide levels. The figures show considerable interpatient variation in the measured variables $\left(\mathrm{ScO}_{2}\right.$ and $\left.\mathrm{BFI}\right)$. Finally, 33 of the $48 \mathrm{pa}-$ tients had a brain MRI immediately before surgery. We are not told what the findings were with respect to white matter injury; it would be of interest to see how $\mathrm{ScO}_{2}$ correlated with the MRI findings.

What is the explanation for the observed decrease in $\mathrm{ScO}_{2}$ ? In their discussion, Lynch and colleagues ${ }^{4}$ state that cerebral oxygen demand may be expected to increase after birth; if cerebral blood flow did not increase in response, then the decrease in $\mathrm{ScO}_{2}$ could reflect decreased oxygen delivery relative to demand. In these patients, however, neither cerebral oxygen consumption nor BFI changed during the study. Assuming that the study methodology is accurate and the resulting measurements reliable, the most likely explanation for the decrease in $\mathrm{ScO}_{2}$ would appear to be a decrease in hemoglobin. During the course of the study, the mean hemoglobin level decreased by $2.1 \mathrm{~g} / \mathrm{dL}$, or approximately $13 \%$ of baseline values, presumably as a result of blood sampling. Although this decrease was not statistically significant, it could well have been clinically significant. Because systemic oxygen saturation and cerebral blood flow were unchanged, the decrease in hemoglobin would have resulted in a proportional decrease in cerebral oxygen delivery. Given constant cerebral oxygen consumption, this would have resulted in a corresponding decrease in cerebral venous oxygen saturation (of $13 \%$ ), which would seem to account for the observed decrease in $\mathrm{ScO}_{2}$ (roughly $8.8 \%$ over 4 days). This study's primary finding may be a reflection of the importance of limiting blood draws and hemodilution in the intensive care unit.

There is certainly intuitive appeal to the hypothesis that a decreasing preoperative cerebral oxygen level could lead to hypoxic-ischemic white matter injury, and that further injury should be avoided by moving to earlier surgery. In this context, it would be reassuring if cerebral oxygenation improved after surgery. Previous work by this group, however, has shown that $\mathrm{ScO}_{2}$ values after an arterial switch are similar to preoperative levels, whereas $\mathrm{ScO}_{2}$ values immediately after stage 1 palliation for HLHS are roughly $8 \%$ lower than preoperative levels, and they decline further during the next 12 hours. ${ }^{2,13}$ Other studies using commercially available NIRS monitors have also found that cerebral oxygen levels decrease after a Norwood procedure, with the decrease ranging from $9 \%$ to $19 \%$ relative to preoperative levels. ${ }^{14-17}$ The effect of surgical timing on the overall health of cerebral oxygenation remains open for further investigation.

What do we know about the relationship of perioperative cerebral oxygenation to brain injury in children undergoing cardiac surgery? Lower perioperative cerebral NIRS values have been associated with postoperative MRI evidence of ischemia, ${ }^{18}$ as well as with worse neurodevelopmental outcome. ${ }^{19-22}$ Lynch and colleagues' previous study ${ }^{2}$ found an association between lower preoperative $\mathrm{ScO}_{2}$ and new or worsened postoperative PVL $(P=.09)$; however, there was no association between postoperative $\mathrm{ScO}_{2}$ and PVL. It is interesting that preoperative $\mathrm{ScO}_{2}$ would be linked to brain injury whereas a lower level just 12 hours later (after surgery) might not be. Lynch and colleagues ${ }^{4}$ suggest that preoperative patients may be particularly vulnerable because of an inability to decrease cerebral vascular resistance and increase cerebral blood flow in response to increasing oxygen demand, or to other stresses such as hypoxia or anemia. ${ }^{4,23}$ Their previous work, however, has shown that preoperative neonates with either TGA or HLHS consistently demonstrate increased cerebral blood flow in response to hypercapnia, ${ }^{8,24}$ indicating preservation of physiologic reserve in the cerebral vascular bed. Certainly, more work is necessary to clarify and reconcile these findings. Cerebral oxygenation, white matter injury, and the link between these remain pieces in a puzzle as yet unsolved.

The days immediately after birth are a physiologically complex time for a neonate with critical heart disease. The CHOP group's optical device seems to be a powerful tool for noninvasive, bedside assessment during this time. Further steps toward validation and application by other groups are desirable. Investigators from $\mathrm{CHOP}$ have made numerous and important contributions to our understanding of brain development, perioperative brain injury, and neurodevelopmental outcomes in infants undergoing congenital heart surgery. Their studies have required an impressive investment of time and resources. Future studies by this group 
will no doubt help further to solve the puzzle of neurodevelopment after infant cardiac surgery.

\section{References}

1. Petit CJ, Rome JJ, Wernovsky G, Mason SE, Shera DM, Nicolson SC, et al. Preoperative brain injury in transposition of the great arteries is associated with oxygenation and time to surgery, not balloon atrial septostomy. Circulation. 2009;119:709-16.

2. Lynch JM, Buckley EM, Schwab PJ, McCarthy AL, Winters ME, Busch DR, et al. Time to surgery and preoperative cerebral hemodynamics predict postoperative white matter injury in neonates with hypoplastic left heart syndrome. J Thorac Cardiovasc Surg. 2014;148:2181-8.

3. Society of Thoracic Surgeons. Congenital heart surgery database, 27th harvest, Fall 2017. Available at: https://www.sts.org/registries-research-center/sts-nationaldatabase/sts-congenital-heart-surgery-database. Accessed December 3, 2017.

4. Lynch JM, Ko T, Busch DR, Newland JJ, Madeline E, Winters ME, et al. Preoperative cerebral hemodynamics from birth to surgery in neonates with critical congenital heart disease. J Thorac Cardiovasc Surg. 2018;156:1657-64.

5. Goff DA, Buckley EM, Durduran T, Wang J, Licht DJ. Noninvasive cerebral perfusion imaging in high-risk neonates. Semin Perinatol. 2010;34:46-56.

6. Hueber DM, Franceschini MA, Ma HY, Zhang Q, Ballesteros JR, Fantini S, et al. Non-invasive and quantitative near-infrared haemoglobin spectrometry in the piglet brain during hypoxic stress, using a frequency-domain multidistance instrument. Phys Med Biol. 2001;46:41-62.

7. Watzman HM, Kurth CD, Montenegro LM, Rome J, Steven JM, Nicolson SC. Arterial and venous contributions to near-infrared cerebral oximetry. Anesthesiology. 2000;93:947-53.

8. Jain V, Buckley EM, Licht DJ, Lynch JM, Schwab PJ, Naim MY, et al. Cerebral oxygen metabolism in neonates with congenital heart disease quantified by MRI and optics. J Cereb Blood Flow Metab. 2014;34:380-8.

9. Buckley EM, Hance D, Pawloski T, Lynch J, Wilson FB, Mesquita RC, et al. Validation of diffuse correlation spectroscopic measurement of cerebral blood flow using phase-encoded velocity mapping magnetic resonance imaging. J Biomed Opt. 2012;17:037007. Erratum in: J Biomed Opt. 2012;17:049805.

10. Kim MN, Durduran T, Frangos S, Edlow BL, Buckley EM, Moss HE, et al. Noninvasive measurement of cerebral blood flow and blood oxygenation using near-infrared and diffuse correlation spectroscopies in critically brain-injured adults. Neurocrit Care. 2010;12:173-80.

11. Buckley EM, Cook NM, Durduran T, Kim MN, Zhou C, Choe R, et al. Cerebral hemodynamics in preterm infants during positional intervention measured with diffuse correlation spectroscopy and transcranial Doppler ultrasound. Opt Express. 2009; 17:12571-81.

12. Zhou C, Eucker SA, Durduran T, Yu G, Ralston J, Friess SH, et al. Diffuse optical monitoring of hemodynamic changes in piglet brain with closed head injury. $J$ Biomed Opt. 2009;14:034015.
13. Buckley EM, Lynch JM, Goff DA, Schwab PJ, Baker WB, Durduran T, et al. Early postoperative changes in cerebral oxygen metabolism following neonatal cardiac surgery: effects of surgical duration. J Thorac Cardiovasc Surg. 2012; 145:196-203, 205.e1; discussion 203-5.

14. Hoffman GM, Stuth EA, Jaquiss RD, Vanderwal PL, Staudt SR, Troshynski TJ, et al. Changes in cerebral and somatic oxygenation during stage 1 palliation of hypoplastic left heart syndrome using continuous regional cerebral perfusion. $J$ Thorac Cardiovasc Surg. 2004;127:223-33.

15. Kussman BD, Gauvreau K, DiNardo JA, Newburger JW, Mackie AS, Booth KL, et al. Cerebral perfusion and oxygenation after the Norwood procedure: comparison of right ventricle-pulmonary artery conduit with modified Blalock-Taussig shunt. J Thorac Cardiovasc Surg. 2007;133:648-55.

16. Li J, Zhang G, Holtby H, Guerguerian AM, Cai S, Humpl T, et al. The influence of systemic hemodynamics and oxygen transport on cerebral oxygen saturation in neonates after the Norwood procedure. J Thorac Cardiovasc Surg. 2008; 135:83-90. 90.e1-2.

17. Uebing A, Furck AK, Hansen JH, Nufer E, Scheewe J, Dütschke P, et al. Perioperative cerebral and somatic oxygenation in neonates with hypoplastic left heart syndrome or transposition of the great arteries. J Thorac Cardiovasc Surg. 2011; 142:523-30.

18. Dent CL, Spaeth JP, Jones BV, Schwartz SM, Glauser TA, Hallinan B, et al. Brain magnetic resonance imaging abnormalities after the Norwood procedure using regional cerebral perfusion. J Thorac Cardiovasc Surg. 2005;130: 1523-30.

19. Kussman BD, Wypij D, Laussen PC, Soul JS, Bellinger DC, DiNardo JA, et al. Relationship of intraoperative cerebral oxygen saturation to neurodevelopmental outcome and brain magnetic resonance imaging at 1 year of age in infants undergoing biventricular repair. Circulation. 2010;122:245-54.

20. Sood ED, Benzaquen JS, Davies RR, Woodford E, Pizarro C. Predictive value of perioperative near-infrared spectroscopy for neurodevelopmental outcomes after cardiac surgery in infancy. J Thorac Cardiovasc Surg. 2013;145:438-45.e1; discussion 444-5.

21. Hoffman GM, Brosig CL, Mussatto KA, Tweddell JS, Ghanayem NS. Perioperative cerebral oxygen saturation in neonates with hypoplastic left heart syndrome and childhood neurodevelopmental outcome. J Thorac Cardiovasc Surg. 2013; 146:1153-64.

22. Hansen JH, Rotermann I, Logoteta J, Jung O, Dütschke P, Scheewe J, et al. Neurodevelopmental outcome in hypoplastic left heart syndrome: impact of perioperative cerebral tissue oxygenation of the Norwood procedure. J Thorac Cardiovasc Surg. 2016;151:1358-66.

23. Lynch JM, Licht DJ. First things first: the importance of the preoperative period for neurocognitive outcomes in hypoplastic left heart syndrome. J Thorac Cardiovasc Surg. 2016;151:1367-8.

24. Durduran T, Zhou C, Buckley EM, Kim MN, Yu G, Choe R, et al. Optical measurement of cerebral hemodynamics and oxygen metabolism in neonates with congenital heart defects. J Biomed Opt. 2010;15:037004. 